\title{
Bexarotene treatment does not clear $\beta$-Amyloid in an AD mouse model and Beagle dogs
}

\author{
Ina Tesseur ${ }^{1,2^{*}}$, Adrian Lo ${ }^{3}$, Anouk Roberfroid ${ }^{1,2}$, Sofie Dietvorst ${ }^{1}$, Bianca Van Broeck ${ }^{4}$, Marianne Borgers ${ }^{4}$, \\ Harrie Gijsen ${ }^{4}$, Diederik Moechars ${ }^{4}$, Marc Mercken ${ }^{4}$, John Kemp ${ }^{4}$, Rudi D'Hooge ${ }^{3}$, Bart De Strooper ${ }^{1,2}$ \\ From Molecular Neurodegeneration: Basic biology and disease pathways \\ Cannes, France. 10-12 September 2013
}

\section{Background}

In our aging society Alzheimer's Disease (AD) is becoming more and more prevalent while effective symptomatic therapeutics remain limited and no cure is available. ApoE4 is the most important genetic risk factor for AD. Previous results by Cramer et al. [1] showed that Bexarotene treatment reduced $A \beta$ in the brain of wild type and $\mathrm{AD}$ model mice via an apoE-mediated clearance mechanism. Bexarotene, an RXR agonist, is an FDA approved drug for cutaneous $\mathrm{T}$ cell lymphoma and hence a preferred candidate for clinical testing. In this study we attempted to replicate the data by Cramer et al. [1].

\section{Methods}

We used captisol ${ }^{\circledR}$ (Cydex Pharmaceuticals), and HP-b-CD/ Tween to dissolve Bexarotene for administration in mice and dogs respectively. For acute experiments we administered a single $100 \mathrm{mg} / \mathrm{kg} /$ p.o. dose of Bexarotene (Ontario Chemical, Inc., Canada) to wild type male Swiss CD1 mice and measured endogenous levels of soluble $A \beta_{x-37}, A \beta_{x-38}, A \beta_{x-40}$ and $A \beta_{x-42}$ in brain at different time points. In Beagle dogs we administered 25 and $100 \mathrm{mg} / \mathrm{kg} /$ p.o. Bexarotene and measured $\mathrm{A} \beta_{\mathrm{x}-37}, \mathrm{~A} \beta_{\mathrm{x}-38}$, $A \beta_{x-40}$ and $A \beta_{x-42}$ levels in CSF. For chronic experiments we administered $100 \mathrm{mg} / \mathrm{kg} /$ day $/$ p.o. Bexarotene for 19 days to 10-months-old male hAPP/PS1 mice.

\section{Results}

In contrast to the published data, we found that acute and chronic treatment with Bexarotene had no significant effects on $A \beta$ levels in the brain of wild type and $A D$ model mice and in Beagle dogs, despite high penetration of the drug into the brain. Although behavioral alterations were observed in $\mathrm{AD}$ model mice, adverse effects of the treatment confounded these observations.

\section{Conclusions}

Drug formulation and pharmacokinetics might explain our contradictory observations with Cramer et al. [1] at least partly. These issues need to be resolved before Bexarotene can be tested in AD.

\section{Authors' details}

${ }^{1} \mathrm{VIB}$ Center for the Biology of Disease, Leuven, Belgium. ${ }^{2} \mathrm{KU}$ Leuven and Universitaire Ziekenhuizen, Center for Human Genetics and Institute of Neuroscience \& Disease (LIND), Leuven, Belgium. ${ }^{3}$ Laboratory of Biological Psychology and Leuven Institute of Neuroscience \& Disease (LIND), University of Leuven, Leuven, Belgium. ${ }^{4}$ Neuroscience Department, Janssen Research and Development, a Division of Janssen Pharmaceutica NV, Beerse, Belgium.

Published: 13 September 2013

\section{Reference}

1. Cramer PE, Cirrito JR: ApoE-directed therapeutics rapidly clear $\beta$-amyloid and reverse deficits in AD mouse models. Science 2012, 335:1503-1506.

\section{doi:10.1186/1750-1326-8-S1-P40}

Cite this article as: Tesseur et al: Bexarotene treatment does not clear $\beta$-Amyloid in an AD mouse model and Beagle dogs. Molecular Neurodegeneration 2013 8(Suppl 1):P40.

${ }^{1} \mathrm{VIB}$ Center for the Biology of Disease, Leuven, Belgium

Full list of author information is available at the end of the article

C 2013 Tesseur et al; licensee BioMed Central Ltd. This is an Open Access article distributed under the terms of the Creative Commons 